\title{
A COMPARATIVE STUDY OF ECHOCARDIOGRAPHIC PARAMETERS IN INDIAN PREGNANT AND NON- PREGNANT WOMEN
}

\author{
Paramita Bhattacharyya1, Vigneshwaran Balasubiramaniyan²
}

${ }^{1}$ Associate Professor, Department of Physiology, Pondicherry Institute of Medical Sciences, Pondicherry.

${ }^{2}$ Senior Resident, Department of Surgical Oncology, All India Institute of Medical Sciences, New Delhi.

\section{ABSTRACT}

\section{BACKGROUND}

Pregnancy is a physiological stressful condition, which is accompanied by changes in cardiovascular parameters to fulfil the requirement of rapidly developing embryo and subsequent foetal growth. Serial evaluation has demonstrated noticeable changes in echocardiographic variables due to haemodynamic overload. Hence, it was proposed to estimate the degree of cardiovascular alteration during pregnancy in South Indian women.

\section{MATERIALS AND METHODS}

Uncomplicated singleton pregnancies in $1^{\text {st }}, 2^{\text {nd }}$ and $3^{\text {rd }}$ trimesters $(n=10$ in each group) along with healthy parous non-pregnant age matched women were used as control $(n=10)$ for this study. After recording baseline ECG and blood pressure, cardiovascular parameters were monitored using M-mode echocardiography and finally data were collected.

\section{RESULTS}

Results were analysed by ANOVA taking $\mathrm{p}<0.05$ as statistically significant. Among cardiac parameters, heart rate showed significantly higher values during pregnancy as gestation advanced $(\mathrm{P}=0.003)$. But ECG could not demonstrate any significant difference throughout pregnancy. All of the echocardiographic parameters definitely showed alteration during various trimesters of pregnancy, but could not reach statistical significance which could be due to small sample size.

\section{CONCLUSION}

In view of these observations, it can be concluded that pregnancy leads to reversible left ventricular hypertrophy as a consequence of augmented venous return, which directly affects stroke volume resulting in physiological alteration in cardiopulmonary status of women. Understanding these alterations will help to extend proper antenatal care for safe motherhood and perinatal outcome.

\section{KEYWORDS}

Echocardiography, Cardiac Output, Stroke Volume, Pregnancy.

HOW TO CITE THIS ARTICLE: Bhattacharyya P, Balasubiramaniyan V. A comparative study of echocardiographic parameters in Indian pregnant and non-pregnant women. J. Evolution Med. Dent. Sci. 2017;6(62):4539-4542, DOI: 10.14260/Jemds/2017/982

\section{BACKGROUND}

Pregnancy is an important phase in a woman's life, which is accompanied by alterations in haemodynamic variables. Echocardiography is a promising non-invasive technique, which is used to investigate the extent of cardiovascular alteration rather than conventional electrocardiograph, particularly for assessment of foetal cardiac functions in early pregnancy..$^{1,2}$ Serial evaluation of echocardiograph variables have demonstrated noticeable changes in maternal cardiac functions, particularly progressive increase in cardiac output associated with valvular orifice area and reversible left ventricular wall hypertrophy with advancing gestation. ${ }^{3,4}$ Normal pregnancy results in temporary decrease in left ventricular systolic function. Left ventricular diastolic dysfunction with preserved left ventricular systolic function by Doppler echocardiography has been used as a clinical tool

Financial or Other, Competing Interest: None.

Submission 29-06-2017, Peer Review 24-07-2017,

Acceptance 29-07-2017, Published 03-08-2017.

Corresponding Author:

Paramita Bhattacharyya,

Associate Professor,

Department of Physiology,

Pondicherry Institute of Medical Sciences,

Ganapathichettikulam,

Pondicherry-605014.

E-mail: drsonamd@yahoo.co.in

DOI: $10.14260 /$ jemds $/ 2017 / 982$

(c) $($ ) $\ominus$ for predicting prognosis of foetal outcome.5,6 Serial evaluation has revealed no change in diastolic function during $2^{\text {nd }}$ and $3^{\text {rd }}$ trimesters of pregnancy, but all inflow velocities increase linearly in the growing foetal heart. ${ }^{7}$

These changes occur gradually in a sequential manner throughout the antenatal period, so that the nutritional status of the growing foetus is properly regulated. Since most of these studies have been conducted to determine the cardiovascular status during pregnancy in Western population, therefore this study is designed for monitoring the cardiac changes during different trimesters of pregnancy in Indian women for comparison. The aim of the present study was to observe ECG and Echocardiographic parameter alterations during different trimesters of pregnancy and to compare with non-pregnant women in healthy South Indian population. It was hypothesised that pregnant women are more prone to develop cardiovascular alteration, particularly during late $2^{\text {nd }}$ and early part of $3^{\text {rd }}$ trimester of pregnancy.

\section{MATERIALS AND METHODS}

This was an observational study involving human subjects only. The study was conducted in the Department of Physiology and Cardiology of a tertiary care centre at Pondicherry. The study protocol was approved by the Institutional Ethical Committee. The study group consisted of thirty healthy pregnant women in the age group of $18-25$ years in $1^{\text {st }}, 2^{\text {nd }}$ and 3 rd trimesters of pregnancy respectively 
(10 in each group) coming for antenatal checkup to the Obstetrics and Gynaecology Department of that Institution, while ten ages matched, healthy, non-pregnant, parous women served as controls. Detailed medical as well as obstetric histories regarding the present and previous pregnancies were obtained from each participant. The participants did not have a history of respiratory or any cardiovascular illness. None of them were taking any medication except vitamins, iron and calcium supplement. There was no history of smoking/alcohol/drug abuse. Pregnancy with diabetes, hypertension and with multiple pregnancies were excluded from this study. An informed written consent was obtained from all the participants after explaining the experimental protocol in detail in their native language.

The study was conducted between 9 - 11 AM to avoid diurnal variation. After a brief period of rest, ECG in Lead II was recorded in supine position using a standard 12-lead computerised ambulatory ECG system by BPL, Cardiart 108T with $1 \mathrm{mv} / \mathrm{cm}$ standardisation and paper speed of 25 $\mathrm{mm} / \mathrm{sec}$. Blood pressure was recorded using Sphygmomanometer apparatus and heart rate was calculated from R-R interval of ECG.

Then the subjects were guided to Dept. of Cardiology, where again after 15 mins of rest transthoracic echocardiogram was performed in the left lateral decubitus position. A 2-Dimensional echocardiogram was obtained selecting the parasternal long axis view by standard adjustment of position and augmentation through aortic window. All measurements were made using the standard procedure and recorded on paper.

Descriptive statistics were expressed as mean and standard deviation. Comparison of various parameters were done between $1^{\text {st }}, 2^{\text {nd }}$ and $3^{\text {rd }}$ trimesters of pregnancy and also with control using one-way analysis of variance (ANOVA) statistical test. The statistical procedures in this study were performed by using GraphPad Instat software version 3. Difference with a ' $p$ ' value $<0.05$ was considered to be statistically significant.

\section{RESULTS}

The general parameters of study group were age $22.6 \pm 2.228$ years, height $154.07 \pm 5.21 \mathrm{cms}$, weight $56.5 \pm 12.02 \mathrm{~kg}$, while that of controls were age $24.73 \pm 0.65$ years, height $152.36 \pm$ $6.22 \mathrm{cms}$ and weight $51.27 \pm 8.20 \mathrm{~kg}$. The systolic blood pressure of the study group was $118.33 \pm 10.20 \mathrm{mmHg}$ and the diastolic blood pressure was $77.53 \pm 6.25 \mathrm{mmHg}$. For control group, the systolic blood pressure was $117.27 \pm 6.47$ $\mathrm{mmHg}$ and diastolic blood pressure was $76.36 \pm 5.05 \mathrm{mmHg}$. The values of cardiac function parameters were compared in between all four groups.

\section{Cardiac Function Parameters in different Trimesters of} Pregnancy

In present study, higher heart rate values were observed in the $2^{\text {nd }}$ and $3^{\text {rd }}$ trimesters of pregnancy when compared to controls, which was statistically significant (Table 1) (Figure 1).

\begin{tabular}{|c|c|c|c|c|c|}
\hline & $\begin{array}{c}\text { HR (BPM) } \\
(\text { Mean } \pm \text { SD) }\end{array}$ & $\begin{array}{c}\text { PR Interval (Sec) } \\
(\text { Mean } \pm \text { SD) }\end{array}$ & $\begin{array}{c}\text { QT Interval (Sec) } \\
(\text { Mean } \pm \text { SD) }\end{array}$ & $\begin{array}{c}\text { SBP (mmHg) } \\
(\text { Mean } \pm \text { SD) }\end{array}$ & $\begin{array}{c}\text { DBP (mmHg) } \\
(\text { Mean } \pm \text { SD) }\end{array}$ \\
\hline Control & $86.50 \pm 14.22$ & $0.14 \pm 0.02$ & $0.37 \pm 0.04$ & $117 \pm 6.75$ & $76 \pm 5.16$ \\
\hline $1^{\text {st }}$ trim & $88.7 \pm 6.36$ & $0.14 \pm 0.02$ & $0.35 \pm 0.02$ & $120 \pm 11.55$ & $77.6 \pm 4.2$ \\
\hline $2^{\text {nd }}$ trim & $101 \pm 11.61$ & $0.14 \pm 0.02$ & $0.34 \pm 0.03$ & $116 \pm 10.75$ & $77 \pm 6.75$ \\
\hline $3^{\text {rd }}$ trim & $103.6 \pm 12.18$ & $0.13 \pm 0.02$ & $0.34 \pm 0.03$ & $119 \pm 8.76$ & $78 \pm 7.89$ \\
\hline P value & 0.003 & 0.857 & 0.117 & 0.783 & 0.896 \\
\hline Significance & S & NS & NS & NS & NS \\
\hline \multicolumn{2}{r}{ Table 1. Cardiac Parameters in different Trimesters of Pregnancy compared with Non-Pregnant Women } \\
\end{tabular}

*All values are expressed as Mean \pm SD $\uparrow$ HR: Heart rate, SBP: Systolic BP, DBP: Diastolic BP, $\ddagger$ S: Significant, NS: Not significant

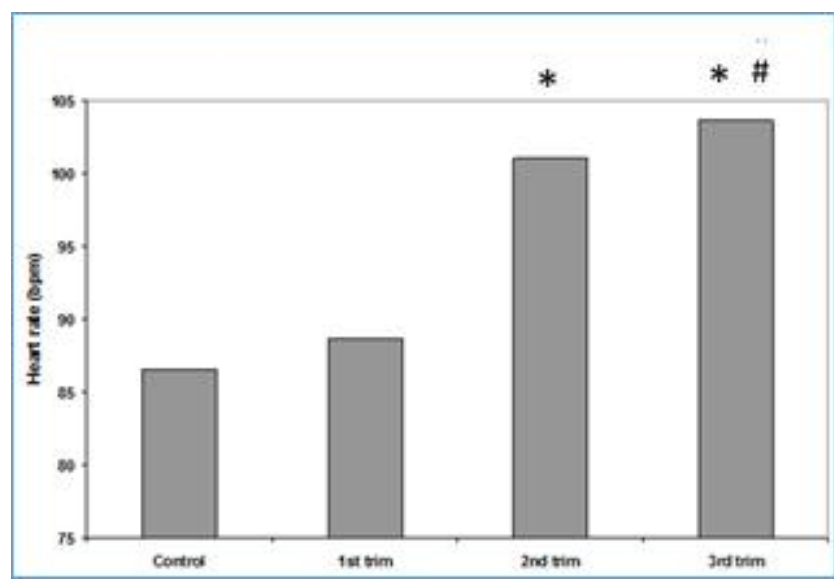

Figure 1. Heart Rate in different Trimesters of Pregnancy compared with Non-Pregnant Women

\section{*Significance with control}

\# Significance with 1 st trimester

But ECG in lead II did not show any significant change. In M-mode Echocardiography, both left atrial and right ventricular internal diameters showed higher values with advancing gestation when compared to control, but was not statistically significant. Similarly, aortic and interventricular septal diameters during diastole did not reveal any significant difference in between the groups (Table 2).

\begin{tabular}{|c|c|c|c|c|}
\hline & $\begin{array}{c}\text { AO }(\mathrm{mm}) \\
\text { (Mean } \pm \text { SD })\end{array}$ & $\begin{array}{c}\text { LA }(\mathrm{mm}) \\
(\text { Mean } \pm \text { SD })\end{array}$ & $\begin{array}{l}\text { RVID (mm) } \\
\text { (Mean } \pm \text { SD) }\end{array}$ & $\begin{array}{l}\text { IVSD }(\mathrm{mm}) \\
\text { (Mean } \pm \text { SD) }\end{array}$ \\
\hline Control & $27.1 \pm 2.3$ & $27.3 \pm 5.71$ & $15.8 \pm 5.7$ & $8.09 \pm 1.108$ \\
\hline $1^{\text {st }}$ trim & $24.6 \pm 4.1$ & $28.3 \pm 4.99$ & $19.2 \pm 4.9$ & $8.14 \pm 1.063$ \\
\hline $2^{\text {nd }}$ trim & $25.2 \pm 2.8$ & $27.1 \pm 3.75$ & $20 \pm 4.4$ & $8.97 \pm 1.08$ \\
\hline $3^{\text {rd }}$ trim & $27 \pm 4.1$ & $30 \pm 4.96$ & $20 \pm 6.1$ & $8.77 \pm 1.16$ \\
\hline P value & 0.28 & 0.54 & 0.26 & 0.19 \\
\hline Significance & NS & NS & NS & NS \\
\hline
\end{tabular}

Table 2. Echocardiography in different Trimesters of Pregnancy compared with Non-Pregnant Women

*All values are expressed as Mean \pm SD.

$\dagger$ AO: Diameter of Aorta, LA: Left atrial diameter, RVID: Right ventricular internal diameter, IVSD: Interventricular septum diameter in diastole. ‡ S: Significant, NS: Not significant. 
Left ventricular posterior wall diameters showed no change in early pregnancy from control, but progressively increased during $2^{\text {nd }}$ and $3^{\text {rd }}$ trimester of pregnancy. This was not statistically significant. Similarly, left ventricular internal diameter in diastole was quantitatively higher in pregnant women than the controls, but was not significant. On the other hand, left ventricular internal diameter in systole comparatively showed higher values in controls suggesting absence of systolic dysfunction in pregnancy. Ejection fraction was also higher throughout pregnancy due to increased stroke volume, but was not statistically significant (Table 3).

\begin{tabular}{|c|c|c|c|c|}
\hline & $\begin{array}{c}\text { LVPW } \\
(\mathbf{m m}) \\
(\mathbf{M e a n} \pm \mathbf{S D})\end{array}$ & $\begin{array}{c}\text { LVIDd (mm) } \\
(\text { Mean } \pm \text { SD) }\end{array}$ & $\begin{array}{c}\text { LVIDs } \\
\mathbf{( m m )} \\
(\mathbf{m e a n} \pm \mathbf{S D})\end{array}$ & $\begin{array}{c}\text { EF \% } \\
(\text { Mean } \pm \text { SD) }\end{array}$ \\
\hline Control & $8.25 \pm 1.08$ & $41.9 \pm 4.93$ & $25.1 \pm 3.4$ & $62.4 \pm 3.09$ \\
\hline $1^{\text {st }}$ trim & $8.34 \pm 1.116$ & $43.3 \pm 5.39$ & $22.8 \pm 5.8$ & $64.8 \pm 2.53$ \\
\hline $2^{\text {nd }}$ trim & $9.17 \pm 1.2$ & $42 \pm 6.41$ & $22.8 \pm 5.9$ & $64.8 \pm 2.53$ \\
\hline $3^{\text {rd }}$ trim & $9.13 \pm 0.8$ & $43.9 \pm 5.32$ & $23.8 \pm 4.02$ & $64.2 \pm 2.89$ \\
\hline P value & 0.1146 & 0.8141 & 0.6929 & 0.1895 \\
\hline $\begin{array}{c}\text { Signi- } \\
\text { ficance }\end{array}$ & NS & NS & NS & NS \\
\hline
\end{tabular}

Table 3. Echocardiography in different Trimesters of Pregnancy compared with Non-Pregnant Women

*All values are expressed as mean \pm SD,

† LVPW: Left ventricular posterior wall thickness.

LVIDd: Left ventricular internal diameter in diastole.

LVIDs: Left ventricular internal diameter in systole.

EF: Ejection fraction.

‡ S: Significant, NS: Not Significant.

Most of the parameters in Echocardiography did not show significant difference among the groups, but trivial Tricuspid Regurgitation was detected in few women with $3^{\text {rd }}$ trimester of pregnancy which was clinically significant.

\section{DISCUSSION}

The anatomical, physiological and biochemical adaptations to pregnancy are profound. Many of these changes begin soon after fertilisation and continue throughout gestation, and in most of the cases these adaptations occur in response to physiological stimuli provided by the foetus. During pregnancy, the cardiovascular system undergoes remarkable physiological alterations in order to meet the demands of enlarged gravid uterus along with its greatly hypertrophied vascular system. Equally astounding is the fact that the pregnant woman returns almost completely to her prepregnancy state after delivery and lactation. The understanding of these adaptations to pregnancy remains a major goal in obstetrics and without such knowledge normal pregnancy can be misinterpreted as disease.

Pregnancy, a chronic natural volume overload state has important effects on haemodynamic variables. Pregnancy causes characteristic, usually reversible, changes in a woman's cardiovascular system due to an increase in total body water by $40 \%-100 \%$ and blood volume by $30 \%-50 \%$ above non-pregnant level. As a consequence, the left ventricular response begins with an increase in heart rate which starts as early as from $1^{\text {st }}$ trimester, further increases during $2^{\text {nd }}$ trimester which is due to increase in venous return in spite of unchanged left ventricular ejection fraction during the entire course of pregnancy. 8,9
The present study strongly supports the above fact where higher heart rate values was observed in $2^{\text {nd }}$ and $3^{\text {rd }}$ trimesters of pregnancy when compared to control, which was statistically significant. Previous ECG studies have revealed widening of QRS complex, prominent $\mathrm{S}$-wave in lead I and conspicuous Q-wave and inverted T-wave in lead III during pregnancy. ${ }^{10}$ But present study did not demonstrate any significant change in lead II ECG other than changes in heart rate. This observation can be explained by the fact that normal pregnancy induces no change in electrocardiography due to altered heart position by gravid uterus. ${ }^{10}$ Blood pressure also remained unaltered due to increase in vascular compliance.

Assessment of anatomical measurements accurately and non-invasively by M-mode echocardiography is universally accepted tool, not only for diagnostic purpose but also for predicting prognosis. Echocardiography has shown significant increase in cardiac output beginning as early as $5^{\text {th }}$ week of gestation and continues to remain elevated throughout pregnancy. This could also be attributed to reduced vascular resistance and an increase in heart rate. ${ }^{11,8}$ During pregnancy due to increase in plasma volume, there is reversible eccentric enlargement in left ventricular wall thickness and valve orifice area, which is suggestive of decreased left ventricular compliance. In addition, left atrial and left ventricular end diastolic diameters are greater reflecting increase in preload which directly affects stroke volume. ${ }^{12}$ Present study also showed a similar report where a small increment was found in left atrial as well as right ventricular internal diameters in pregnancy with advancing gestation. Though non-significant but the slight increase in atrial size during pregnancy can be interpreted as an indicator of left ventricular filling status, which reflects that both preload and circulating blood volume increase during pregnancy. 4 This augmentation of preload directly affects stroke volume, which ultimately leads to reversible physiological left ventricular hypertrophy as well as progressive increase in valvular orifice area during pregnancy.12,13 Though this study could not demonstrate any alteration in aortic and interventricular septal diameters so much, but the trivial tricuspid regurgitation which was detected by echocardiography in a few women with late pregnancy was clinically significant and because of this extra load on right ventricle the right ventricular internal diameter might have altered.

Present study also showed an increment in left ventricle internal diameter during diastole as well as reduction in left ventricle internal diameter during systole in pregnant women than control. Though no statistical significance, still it implies that there is an enhancement of intrinsic myocardial contractility due to increased stroke volume, which ultimately leads to both augmentation of left ventricle diastolic pattern and temporary decrease in systolic function. 8,13

\section{Limitations}

Overall, this study could not demonstrate any significant changes in echocardiographic variables during different trimesters of pregnancy. This can be explained by the fact that present study was conducted with a small number of participants within a stipulated time period of 2 months duration, which was insufficient to alter the cardiovascular 
status of pregnancy. Also because of the limitation in time factor, it was not possible to follow up all echocardiographic parameters in the same pregnant woman from beginning of first trimester throughout pregnancy till delivery unlike all previous studies, which was pertaining to almost 1-year duration. Moreover, in this study age matched healthy parous women were taken as control group, but in other studies, control was chosen selectively from postpartum group.

\section{CONCLUSION}

In conclusion, it can be stated that pregnancy, a physiological chronic volume overload state has important effects on haemodynamic and functional parameters in each trimester. But the susceptibility to such alterations are variable. Pregnancy leads to reversible physiological alteration in cardiopulmonary status of women as a consequence of mechanical and complex hormonal factors due to progressive distension of gravid uterus. The cardiopulmonary status of women during pregnancy are also modulated by external factors such as racial, genetic background, nutritional as well as socio-economic status. Though the cardiopulmonary physiology is definitely altered by pregnancy, but not compromised as such in normal women. Therefore, understanding this basic physiology will help us not only to avoid misinterpretation considering pregnancy as a disease condition but also to extend proper antenatal care to susceptible individuals to ensure maternal and foetal wellbeing. Due to limited time duration, it was not possible to follow up the nature of these alterations and their subsequent effect during the course of pregnancy, therefore it will be reasonable to conduct a detailed and prospective study in future to understand the basic mechanism underlying it.

\section{ACKNOWLEDGEMENT}

The authors are extremely grateful to Dr. (Late) Susheela Veliath, Professor and Head, Department of Physiology and Dr. N. Krishnamoorthy, Retired Professor of Physiology for their constant encouragement, guidance and valuable suggestions to complete this work successfully. Authors also express heartfelt gratitude to Dr. Mark Christopher M.D, D.M (Cardiology) for his infinite patience in performing echocardiography of all the participants in spite of his busy and hectic schedule. Finally, authors would like to thank all participants without whom the study would not have been possible.

\section{REFERENCES}

[1] Russell NE, McAuliffe FM. First-trimester fetal cardiac function. J Ultrasound Med 2008;27(3):379-83.
[2] Haak MC, van Vugt JM. Echocardiography in early pregnancy: review of literature. J Ultrasound Med 2003;22(3):271-80.

[3] Mabie WC, DiSessa TG, Crocker LG, et al. A longitudinal study of cardiac output in normal human pregnancy. Am J Obstet Gynecol 1994;170(3):849-56.

[4] Robson SC, Hunter S, Boys RJ, et al. Serial study of factors influencing changes in cardiac output during human pregnancy. Am J Physiol 1989;256(4 Pt 2):H1060-5.

[5] De Conti F, Da Cortà R, Monte DD, et al. Left ventricular diastolic function in pregnancy-induced hypertension. Ital Heart J 2003;4(4):246-51.

[6] Sugioka K, Takemoto Y, Yoshikawa J. Diagnosis of left ventricular diastolic dysfunction by Doppler echocardiography. Nippon Rinsho 2004;62(1):71-9.

[7] Tulzer G, Khowsathit $P$, Gudmundsson $S$, et al. Diastolic function of the fetal heart during second and third trimester: a prospective longitudinal Dopplerechocardiographic study. Eur J Pediatr 1994;153(3):151-4.

[8] Thornburg KL, Jacobson SL, Giraud GD, et al. Haemodynamic changes in pregnancy. Semin Perinaotol 2000;24(1):11-4.

[9] Schannwell CM, Zimmermann T, Schneppenheim M, et al. Left ventricular hypertrophy and diastolic dysfunction in healthy pregnant women. Cardiology 2002;97(2):73-8.

[10] Oktay C, Kesapli M, Altekin E. Wide-QRS complex tachycardia during pregnancy: treatment with cardioversion and review. Am J Emergency Med 2002;20(5):492-3.

[11] Gilson GJ, Samaan S, Crawford MH, et al. Changes in haemodynamics, ventricular remodeling and ventricular contractility during normal pregnancy: a longitudinal study. Obstet Gynecol 1997;89(6):95762.

[12] Mesa A, Jessurun C, Hernandez A, et al. Left ventricular diastolic function in normal human pregnancy. Circulation 1999;99(4):511-7.

[13] Schannwell CM, Schoebel FC, Zimmermann T, et al. Left ventricular diastolic function in normal pregnancy. A prospective study using M-mode echocardiography and Doppler echocardiography. Dtsch Med Wochenschr 2000;125(37):1069-73. 